\title{
Should the left gastric artery lymph node be considered as the predictive lymph node for extra-gastric lymph node metastases?
}

\author{
Weilin Sun $^{1,2,3 \#}$, Jingyu Deng ${ }^{1,2,3 \#}$, Wenting $\mathrm{He}^{1,2,3}$, Jinyuan Liu ${ }^{1,2,3}$, Shiwei Guo ${ }^{1,2,3}$, Pengfei Gu ${ }^{1,2,3}$, \\ Zizhen $\mathrm{Wu}^{1,2,3}$, Han Liang ${ }^{1,2,3}$
}

${ }^{1}$ Department of Gastroenterology, Tianjin Medical University Cancer Institute and Hospital, National Clinical Research Center for Cancer, Tianjin, China; ${ }^{2}$ Key Laboratory of Cancer Prevention and Therapy, Tianjin, China; ${ }^{3}$ Tianjin's Clinical Research Center for Cancer, Tianjin, China

Contributions: (I) Conception and design: J Deng, H Liang; (II) Administrative support: H Liang; (III) Provision of study materials or patients: J Deng, H Liang; (IV) Collection and assembly of data: W Sun, W He, J Liu, S Guo, P Gu, Z Wu; (V) Data analysis and interpretation: W Sun, J Deng, W He; (VI) Manuscript writing: All authors; (VII) Final approval of manuscript: All authors.

\#These authors equally contributed to the work.

Correspondence to: Jingyu Deng; Han Liang. Department of Gastroenterology, Tianjin Medical University Cancer Institute and Hospital, National Clinical Research Center for Cancer, Tianjin, China; Key Laboratory of Cancer Prevention and Therapy, Tianjin, China; Tianjin's Clinical Research Center for Cancer, Tianjin, China. Email: dengery@126.com; tjlianghan@126.com.

Background: To validate the prognostic impacts of the left gastric artery lymph node (No. 7 LN) metastasis and investigate whether the No. $7 \mathrm{LN}$ metastasis should be considered as the predictive LN for extra-gastric LN metastases.

Methods: Between January 2003 and December 2011, a total of 1,586 patients who underwent R0 gastrectomy were retrospected. Patients with LN metastases were divided into three groups: (I) patients with only peri-gastric LN metastases (peri-gastric group); (II) patients with peri-gastric and only No. 7 LN metastases (No. 7 group); and (III) patients with other extra-gastric LN metastases (extra-gastric group). Propensity score matching (PSM) was adopted to accurately evaluate prognoses of all patients after surgery. Results: Of 1,586 patients, 235 (14.82\%) were pathologically identified to present with the No. 7 LN metastases. Patients with the No. 7 LN metastases presented the significantly lower survival rate both before and after adjustment by pTNM stage, compared to those without the No. 7 LN metastases. Patients in the No. 7 group were identified to present the significant lower survival rate than those in the peri-gastric group, and to present the similar median overall survival (OS) to those in the extra-gastric group. In addition, patients with extra-gastric LN except No. 7 LN metastases failed to show any superiority of survival outcomes, compared with those with extra-gastric LN metastases including the No. 7 LN metastasis.

Conclusions: The No. 7 LN metastases had the crucial survival implications. Nevertheless, the No. 7 LN failed to be considered as the predictive LN for the extra-gastric LN metastases in gastric cancer (GC).

Keywords: Stomach; neoplasm; lymph node (LN); prognosis; left gastric artery

Submitted Jan 03, 2020. Accepted for publication May 09, 2020.

doi: $10.21037 /$ atm-19-4786a

View this article at: http://dx.doi.org/10.21037/atm-19-4786a

\section{Introduction}

Gastric cancer (GC) has a tendency toward lymphatic metastasis due to the abundant lymphatic vessels in the stomach wall. Lymphadenectomy has an important clinical impact, and the extent of lymphadenectomy may directly influence the patients' survival outcome after radical gastronomy. The No. 7 station (along the left gastric artery) is a specific anatomic lymph node (LN) station located between peri-gastric LNs and other extra-gastric LNs in GC patients. In theory, the No. $7 \mathrm{LN}$ station is not defined as one of the peri-gastric LN stations based on its anatomical location, despite the high incidence of metastatic 
incidents occurring close to the peri-gastric LN stations $(1,2)$. According to the latest Union for International Cancer Control/American Joint Committee on Cancer (UICC/AJCC) guidelines for GC (3), No. 7 station LNs should be considered while evaluating the extent of D2 lymphadenectomy. However, in the latest edition of the Japanese Gastric Cancer Treatment Guidelines (the $3^{\text {rd }}$ edition) and the $14^{\text {th }}$ edition of the Japanese General Rules for Gastric Cancer Study, the No. 7 LN station was assigned to the range of both D1 plus and D2 lymphadenectomy $(4,5)$. That is to say, GC patients with cT1N0M0 stage disease might undergo different lymphadenectomies in different countries. Therefore, the clinical significance of the No. 7 station for GC patients remains controversial according to the current literature $(1,6-9)$.

In order to evaluate precisely the range of $\mathrm{LN}$ metastasis, the concept of sentinel LNs (SLNs) arised, which was defined as the first draining LNs that obtain lymphatic flow from a primary tumor (10). The concept of SLNs is gradually being accepted and applied to GC, and novel techniques for SLN mapping have been developed, such as methods using dyes or radioisotopes (11-13). However, identifying specific SLNs in cases of GC is challenging, due to the complexity of lymphatic drainage from the gastric area $(14,15)$. And SLNs seldom provides much benefit to predict the extra-gastric LN station or distant metastasis. Thus, new predictive factors are needed to identify the extra-gastric LN or distant metastasis. On the other hand, multiple recent studies have reported that the No. $7 \mathrm{LN}$ station was the most common extra-gastric LN station to be involved in metastasis, regardless of tumor location (16-18). Taking anatomical location and high incidence of metastatic incidents of No. 7 LN station into account, we hypothesized that the No. 7 station should be on the main lymph routine and be a predictive $\mathrm{LN}$ for extra-gastric $\mathrm{LN}$ metastases. However, few studies have evaluated whether the No. $7 \mathrm{LN}$ station might be considered as the predictive marker for determining the extent of lymphadenectomy in GC patients.

In this study, we aimed to demonstrate the prognostic impact of the No. $7 \mathrm{LN}$ station and to validate whether the No. 7 LN should be considered as the predictive LN for other extra-gastric LN metastases in GC patients.

We present the following article in accordance with the STROBE reporting checklist (available at http://dx.doi. org/10.21037/atm-19-4786a).

\section{Methods}

\section{Patients}

Between January 2003 and December 2011, a total of 1,923 GC patients who underwent R0 gastrectomy at Tianjin Medical University Cancer Institute and Hospital. The clinicopathologic date and fellow-up records of 1,923 GC patients were retrospectively reviewed after receiving Institutional Review Board approval. Eligibility criteria included: (I) proven histologically primary gastric carcinoma; (II) curative gastrectomy with pathologically negative resection margins (R0 resection); (III) remaining alive at the initial hospital stay and the first postoperative month. The exclusion criteria were: (I) distant metastases or peritoneal dissemination; (II) skip LN metastases; (III) posterior (No. 8p, No. 12b/p, No. 13, and No. 14v) or para-aortic (No. 16a2, and No. 16b1) LNs metastases; (IV) history of gastrectomy or other malignancies; (V) history of neoadjuvant chemotherapy; and (VI) loss of follow up.

Ultimately, 1,586 patients in total were included in this study (Figure S1). Of these 1,586 GC patients, 897 (56.56\%) presented LN metastases, and 235 (14.82\%) presented the No. $7 \mathrm{LN}$ metastases. According to the range of LN involved, all included patients with $\mathrm{LN}$ involvement were divided into three groups of cases: (I) LN metastases limited to peri-gastric area (peri-gastric group), (II) peri-gastric LN metastases with only No. 7 LN metastases (No. 7 group), and (III) peri-gastric LN metastases with other extra-gastric LN metastases (extra-gastric group).

The study was approved by Tianjin Medical University Cancer Institute and Hospital ethics committees (No. bc2019087). All patients provided written informed consent before any enrolling procedures were initiated.

\section{Surgical management}

All included patients underwent the curative gastrectomy with lymphadenectomy for GC. Curative resection was defined as the complete absence of grossly visible tumor tissue and pathologically negative resection margins. The $\mathrm{pT}$ stage and $\mathrm{pN}$ stage were according to AJCC TNM staging system (19). The nodes staging system was defined according to the $13^{\text {th }}$ edition of JCGC (Japanese Gastric Cancer Association, JCGC) (20). Peri-gastric LN stations were defined as n1-tire (from No. 1 to No. 6) LN station, whereas LN stations along the left gastric artery (No. 7), 
along the common hepatic artery (No. 8a), the celiac axis (No. 9), the splenic hilar(No. 10), splenic artery (No. 11) and the proper hepatic artery (No. 12a) were defined as extra-gastric LN stations. Skip LN metastases were defined as the presence of a metastatic LN in an extra-gastric area without peri-gastric LN involvement (21).

\section{Follow-up}

After curative surgery for GC, all patients were followedup every 3 or 6 months for 2 years, and annually, thereafter, until death or deadline. The median follow-up time for the entire cohort was 33 months (range, 2 to 148 months). The deadline of follow-up in this study was December 2015. At every visit, patients underwent ultrasonography, computed tomography, chest radiography, and endoscopy. Overall survival (OS) served as the primary end-point, and was defined as the time interval between the date of surgery and the date of either death as a result of GC or the last followup. During the follow-up period, 1,229 patients $(77.49 \%)$ died.

\section{Propensity score matching (PSM)}

To overcome possible selection bias, one-to-one matching using PSM was performed in this study $(22,23)$. The propensity score, defined as the conditional probability of patients being treated given the covariates, could be used to balance the covariates in two groups and therefore reduce such bias $(24,25)$. It had also been reported that potential confounding variables that could be unrelated to the exposure but related to the outcome should be included in the propensity score model, and that this would decrease the variance of an estimated exposure effect without increasing the bias (26). The propensity scores were estimated by using a non-parsimonious multiple logistic regression model. In this study, the No. 7 LN metastases were significant correlated with $\mathrm{pN}$ stage (spearman $\mathrm{r}=0.424, \mathrm{P}<0.001$ ). Therefore, the following covariates were selected for the calculation of the propensity score: gender, age, tumor location, tumor size, pT stage, Borrmann type, Lauren type, vasculolymphatic invasion, neurological invasion and adjuvant chemotherapy.

\section{Statistical analysis}

The $\chi^{2}$ or Fisher's exact test used for categorical variables, and a $t$ test was used for continuous variables. Factors that showed significant difference in the univariate analysis $(\mathrm{P}<0.05)$ were included in the multivariate analysis. Multivariate analysis was performed using a logistic regression model for the evaluation of the predictive risk factors. OS was determined using the KaplanMeier method, and a log-rank test was used to evaluate significance. Multivariate analyses of OS were performed to calculate the hazard ratios (HRs) and 95\% confidence intervals (CIs) through the Cox regression model. In all statistical analyses, significance was defined as $\mathrm{P}<0.05$ (twosided). All statistical analyses were performed using the statistical analysis program package SPSS version 24.0 (SPSS, Chicago, IL, United States).

\section{Results}

\section{Survival analysis of the No. 7 station LN metastases}

The prognostic impact of the No. 7 station LN metastases in patients was determined. During the follow-up, 1,229 patients died and 357 patients remained alive. KaplanMeier analyses showed a significant difference in terms of prognosis between the No. 7 LN-negative (no metastasis) and the No. 7 LN-positive (metastases) patients (HR 1.795, 95\% CI: 1.545-2.086, $\mathrm{P}<0.001$, Figure $1 A)$. The median survival time of No. 7 LN-negative and No. 7 LNpositive patients was $38 \pm 1.757$ vs. $18 \pm 1.730$ months. That survival difference was also significant after stratification by pTNM stage (III stage with vs. without the No. 7 LN metastases: HR 1.225, 95\% CI: 1.043-1.439, P=0.014, Figure $1 B$ ). Although the small-scale samples resulted in the non-significant difference in patients with II stage (II stage with vs. without the No. 7 metastases, HR 1.392, 95\% CI: $0.763-2.539, \mathrm{P}=0.281$ ), the potential tendency of survival difference might be observed in the Figure $1 B$.

\section{PSM among peri-gastric, the No. 7 and extra-gastric group}

Table 1 showed the clinical characteristics of GC patients of peri-gastric group and the No. 7 group. Before PSM, some significant differences were observed between two groups: tumor location $(\mathrm{P}<0.001)$, and Borrmann type $(\mathrm{P}=0.119)$. The differences between peri-gastric and the No. 7 groups were well balanced after PSM: tumor location $(\mathrm{P}=0.858)$, and Borrmann type $(\mathrm{P}=0.425)$. Ultimately, 138pairs patients were analyzed after PSM. As Table 2 showed, the differences between the No. 7 and extra-gastric group were also 
A

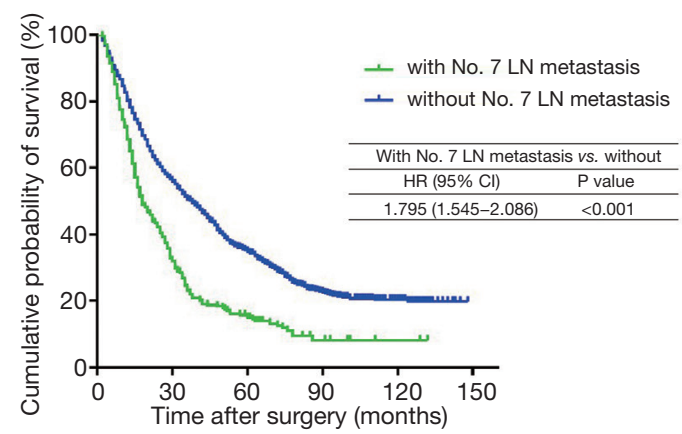

No. at risk

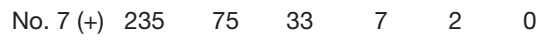

No. 7 (-) $1,351 \quad 756 \quad 453 \quad 153 \quad 40 \quad 0$

B

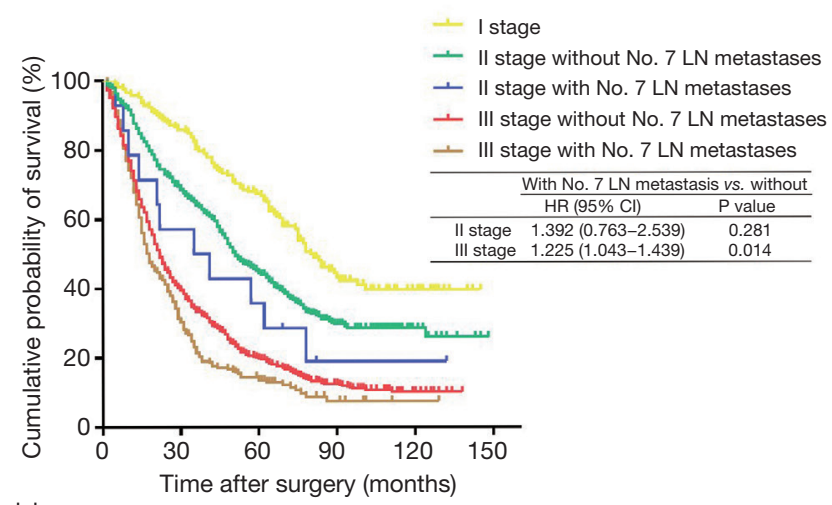

No. at risk

$\begin{array}{lccccrl}\text { I stage } & 172 & 148 & 111 & 42 & 15 & 0 \\ \text { II stage with No. 7(-) } & 488 & 335 & 207 & 62 & 13 & 0 \\ \text { II stage with No. 7 (+) } & 14 & 8 & 5 & 1 & 1 & 0 \\ \text { III stage with No. 7(-) } & 691 & 273 & 135 & 49 & 12 & 0 \\ \text { III stage with No. 7(+) } & 221 & 67 & 28 & 6 & 1 & 0\end{array}$

Figure 1 Kaplan-Meier curves for overall survival (A) between patients with No. 7 LN metastasis and patients without No. 7 LN metastasis; (B) after adjustment by pTNM stage. LN, lymph node. No. 7 LN, LN along the left gastric artery. No. 7 (+), with No. 7 LN metastasis; No. 7 (-), without No. 7 LN metastasis; HR, hazard ratio; CI, confidence interval.

immensely reduced after PSM: tumor location (before $v s$. after: $\mathrm{P}<0.001$ vs. $\mathrm{P}=0.125$ ), tumor size (before vs. after: $\mathrm{P}=0.104$ vs. $\mathrm{P}=0.286$ ), $\mathrm{p}$ T stage (before vs. after: $\mathrm{P}=0.071$ vs. $\mathrm{P}=0.106$ ), and Borrmann type (before vs. after: $\mathrm{P}<0.001$ vs. $\mathrm{P}=0.207$ ). Ultimately, 113 pair patients were enrolled after PSM.

\section{Prognostic analysis before and after PSM}

The prognostic analysis among peri-gastric, the No. 7 and extra-gastric groups was performed (Figure $2 A$ ). During the follow-up, the survival rates of these three groups were respectively: $15.4 \%$ (81/524), 13.04\% (21/161) and $10.38 \%(22 / 212)$. And the median survival time were respectively: $24 \pm 1.381,18 \pm 2.819$, and $18 \pm 1.266$ months. Before matching, Kaplan-Meier curve showed a significant difference in terms of prognosis between the No. 7 group and peri-gastric group (HR 1.227, 95\% CI: 1.014-1.484, $\mathrm{P}=0.035$, Figure $2 B$ ), but no significant difference in survival outcomes between the No. 7 group and extra-gastric group (HR 1.084, 95\% CI: 0.872-1.349, $\mathrm{P}=0.467$, Figure $2 C$ ). After PSM, the OS was also significantly poorer in the No. 7 group compared with peri-gastric group (HR 1.360, 95\% CI: $1.051-1.761, \mathrm{P}=0.020$, Figure $2 D$ ). Similarly, the close survival rate between No. 7 group and extra-gastric group (HR 1.123, 95\% CI: 0.851-1.482, $\mathrm{P}=0.411$, Figure $2 E$ ) was observed after PSM. 
Table 1 Clinical characteristics of patients of peri-gastric group and No. 7 group before and after propensity score matching

\begin{tabular}{|c|c|c|c|c|c|c|}
\hline Characteristics & \multicolumn{3}{|c|}{ Entire cohort } & \multicolumn{3}{|c|}{ Propensity score matching } \\
\hline \multicolumn{7}{|l|}{ Gender } \\
\hline Female & 152 & 42 & & 30 & 39 & \\
\hline \multicolumn{7}{|l|}{ Age (years) } \\
\hline$\geq 60$ & 307 & 97 & & 91 & 82 & \\
\hline \multicolumn{7}{|l|}{ Tumor location } \\
\hline Upper $1 / 3$ & 156 & 77 & $<0.001^{\star \star}$ & 55 & 59 & 0.858 \\
\hline Middle $1 / 3$ & 39 & 8 & & 9 & 8 & \\
\hline$\leq 5.0$ & 254 & 82 & 0.585 & 74 & 69 & 0.547 \\
\hline$>5.0$ & 270 & 79 & & 64 & 69 & \\
\hline \multicolumn{7}{|l|}{ pT stage } \\
\hline Pt1a & 1 & 0 & $0.660^{\mathrm{b}}$ & 1 & 0 & $0.962^{\mathrm{b}}$ \\
\hline Pt1b & 2 & 2 & & 1 & 2 & \\
\hline Pt2 & 37 & 12 & & 11 & 9 & \\
\hline Pt3 & 32 & 7 & & 6 & 5 & \\
\hline Pt4a & 436 & 137 & & 116 & 119 & \\
\hline \multicolumn{7}{|l|}{ Lauren type $^{c}$} \\
\hline Intestinal & 273 & 79 & 0.683 & 70 & 66 & $0.858^{\mathrm{b}}$ \\
\hline Diffuse & 230 & 78 & & 67 & 71 & \\
\hline Mixed & 9 & 3 & & 1 & 1 & \\
\hline \multicolumn{7}{|c|}{ Vasculolymphatic invasion } \\
\hline No & 519 & 157 & $0.273^{\mathrm{a}}$ & 137 & 135 & $0.614^{\mathrm{a}}$ \\
\hline Yes & 5 & 4 & & 1 & 3 & \\
\hline \multicolumn{7}{|c|}{ Neurological invasion ${ }^{c}$} \\
\hline No & 519 & 158 & $1.000^{\mathrm{b}}$ & 135 & 136 & $0.481^{\mathrm{a}}$ \\
\hline Yes & 3 & 1 & & 2 & 0 & \\
\hline \multicolumn{7}{|c|}{ Adjuvant chemotherapy } \\
\hline No & 204 & 60 & 0.704 & 61 & 55 & 0.464 \\
\hline Yes & 320 & 101 & & 77 & 83 & \\
\hline
\end{tabular}

${ }^{\mathrm{a}}$, continuity correction analysis; ${ }^{\mathrm{b}}$, fisher exact analysis; ${ }^{\mathrm{c}}$, some data missed; ${ }^{* *}, \mathrm{P}<0.001$. LN, lymph node. 
Page 6 of 14

Sun et al. No. 7 lymph node metastasis for gastric cancer

Table 2 Clinical characteristics of patients of No. 7 group and extra-gastric group before and after propensity score matching

\begin{tabular}{|c|c|c|c|c|c|c|}
\hline \multirow{2}{*}{ Characteristics } & \multicolumn{3}{|c|}{ Entire cohort } & \multicolumn{3}{|c|}{ Propensity score matching } \\
\hline & No. $7(n=161)$ & Extra-gastric $(\mathrm{n}=212)$ & $P$ value & No. $7(n=113)$ & Extra-gastric $(n=113)$ & $P$ value \\
\hline \multicolumn{7}{|l|}{ Gender } \\
\hline Male & 119 & 156 & 0.943 & 84 & 86 & 0.758 \\
\hline Female & 42 & 56 & & 29 & 27 & \\
\hline \multicolumn{7}{|l|}{ Age (years) } \\
\hline$<60$ & 64 & 97 & 0.246 & 54 & 46 & 0.284 \\
\hline$\geq 60$ & 97 & 115 & & 59 & 67 & \\
\hline \multicolumn{7}{|l|}{ Tumor location } \\
\hline Upper $1 / 3$ & 77 & 35 & $<0.001^{\star \star}$ & 34 & 33 & 0.125 \\
\hline Middle 1/3 & 8 & 28 & & 5 & 12 & \\
\hline Lower $1 / 3$ & 45 & 96 & & 45 & 50 & \\
\hline More than $2 / 3$ & 31 & 53 & & 29 & 18 & \\
\hline \multicolumn{7}{|l|}{ Tumor size (cm) } \\
\hline$\leq 5.0$ & 82 & 90 & 0.104 & 56 & 48 & 0.286 \\
\hline$>5.0$ & 79 & 122 & & 57 & 65 & \\
\hline \multicolumn{7}{|l|}{ pT stage } \\
\hline pT1a & 0 & 1 & $0.071^{\mathrm{b}}$ & 0 & 1 & $0.106^{b}$ \\
\hline $\mathrm{pT} 1 \mathrm{~b}$ & 2 & 1 & & 0 & 1 & \\
\hline pT2 & 12 & 7 & & 9 & 6 & \\
\hline pT3 & 7 & 10 & & 1 & 4 & \\
\hline pT4a & 137 & 179 & & 102 & 95 & \\
\hline pT4b & 3 & 14 & & 1 & 6 & \\
\hline \multicolumn{7}{|l|}{ Borrmann type } \\
\hline 1 & 13 & 8 & $<0.001^{\star \star}$ & 4 & 8 & 0.207 \\
\hline II & 58 & 44 & & 34 & 22 & \\
\hline III & 74 & 113 & & 62 & 66 & \\
\hline IV & 16 & 47 & & 13 & 17 & \\
\hline \multicolumn{7}{|l|}{ Lauren type $^{c}$} \\
\hline Intestinal & 79 & 90 & 0.250 & 48 & 43 & $0.170^{b}$ \\
\hline Diffuse & 78 & 111 & & 64 & 64 & \\
\hline Mixed & 3 & 9 & & 1 & 6 & \\
\hline \multicolumn{7}{|c|}{ Vasculolymphatic invasion } \\
\hline No & 157 & 210 & $0.449^{\mathrm{a}}$ & 111 & 112 & $1.000^{\mathrm{a}}$ \\
\hline Yes & 4 & 2 & & 2 & 1 & \\
\hline \multicolumn{7}{|c|}{ Neurological invasion ${ }^{c}$} \\
\hline No & 158 & 210 & $1.000^{\mathrm{a}}$ & 112 & 111 & $0.481^{\mathrm{a}}$ \\
\hline Yes & 3 & 2 & & 0 & 2 & \\
\hline \multicolumn{7}{|c|}{ Adjuvant chemotherapy } \\
\hline No & 60 & 78 & 0.925 & 44 & 37 & 0.332 \\
\hline Yes & 101 & 134 & & 69 & 76 & \\
\hline
\end{tabular}

${ }^{a}$, continuity correction analysis; ${ }^{b}$, fisher exact analysis; ${ }^{c}$, some data missed; ${ }^{\star *}, \mathrm{P}<0.001$. LN, lymph node. 
A

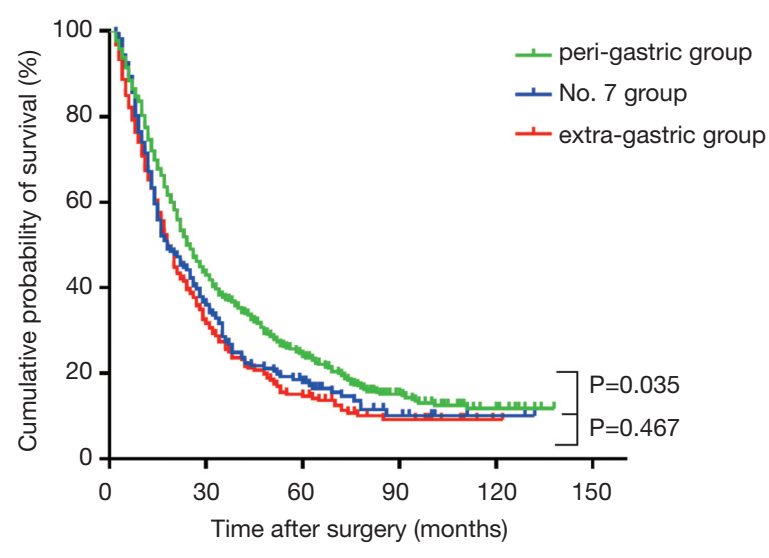

B

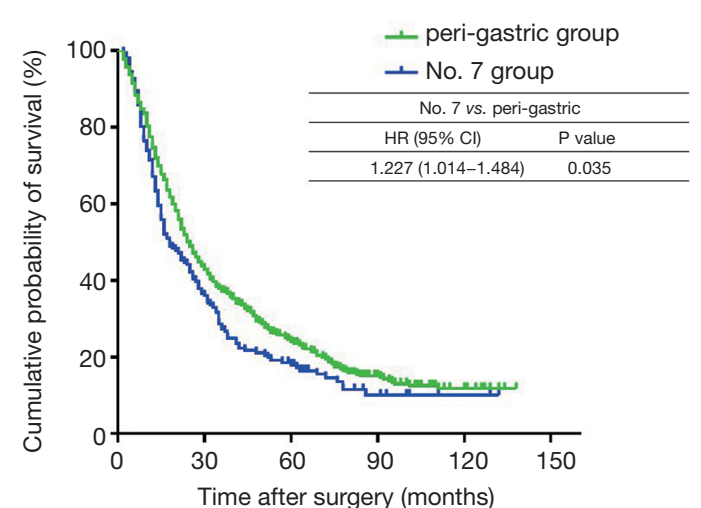

No. at risk

$\begin{array}{lllllll}\text { peri-gastric } & 524 & 225 & 121 & 39 & 11 & 0\end{array}$

$\begin{array}{lllllll}\text { No. } 7 & 161 & 58 & 27 & 7 & 2 & 0\end{array}$

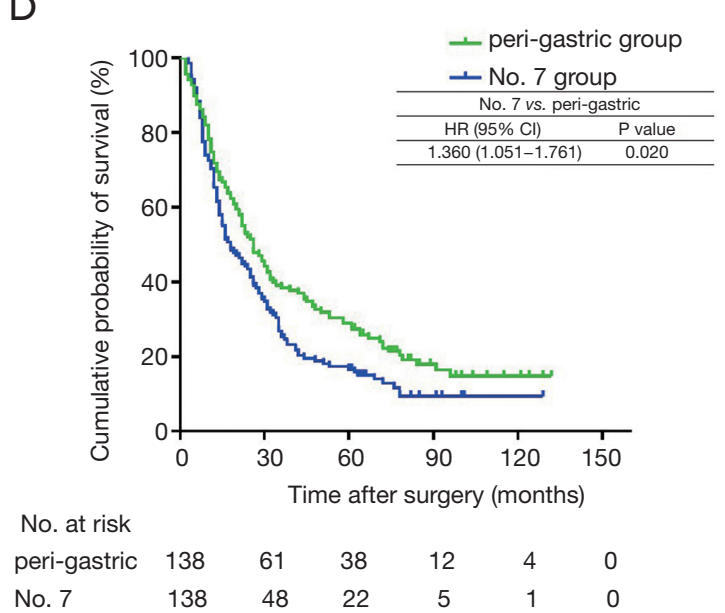

C

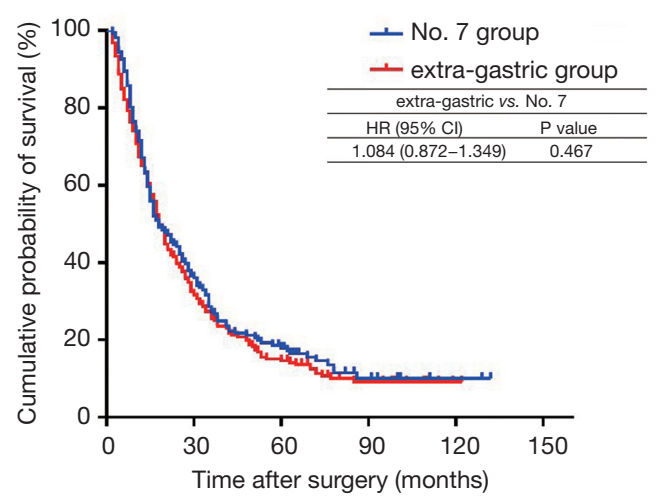

No. at risk

$\begin{array}{lllllll}\text { No. } 7 & 161 & 58 & 27 & 7 & 2 & 0\end{array}$

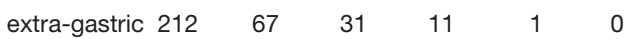

E

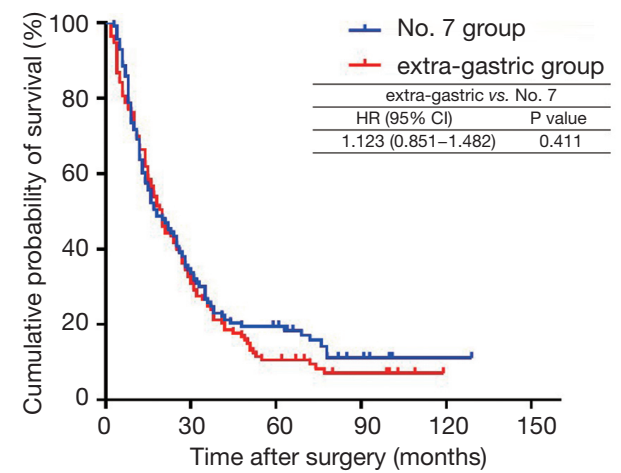

No. at risk

$\begin{array}{lllllll}\text { No. } & 113 & 38 & 20 & 5 & 1 & 0\end{array}$

extra-gastric $\begin{array}{llllll}113 & 35 & 12 & 5 & 0 & 0\end{array}$

Figure 2 Kaplan-Meier curves for overall survival (A) among peri-gastric group, No. 7 group and extra-gastric group; (B) between perigastric group and No. 7 group before PSM; (C) between No. 7 and extra-gastric group before PSM; (D) between peri-gastric group and No. 7 group after PSM; (E) between No. 7 and extra-gastric group after PSM. PSM, propensity score matching; LN, lymph node; No. 7 LN, LN along the left gastric artery; HR, hazard ratio; CI, confidence interval. 
A

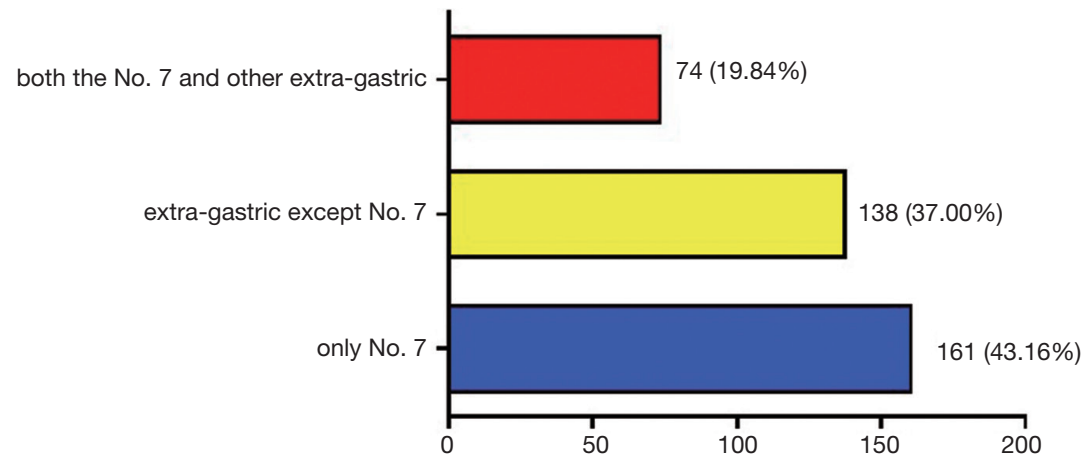

$\mathrm{N}$

B

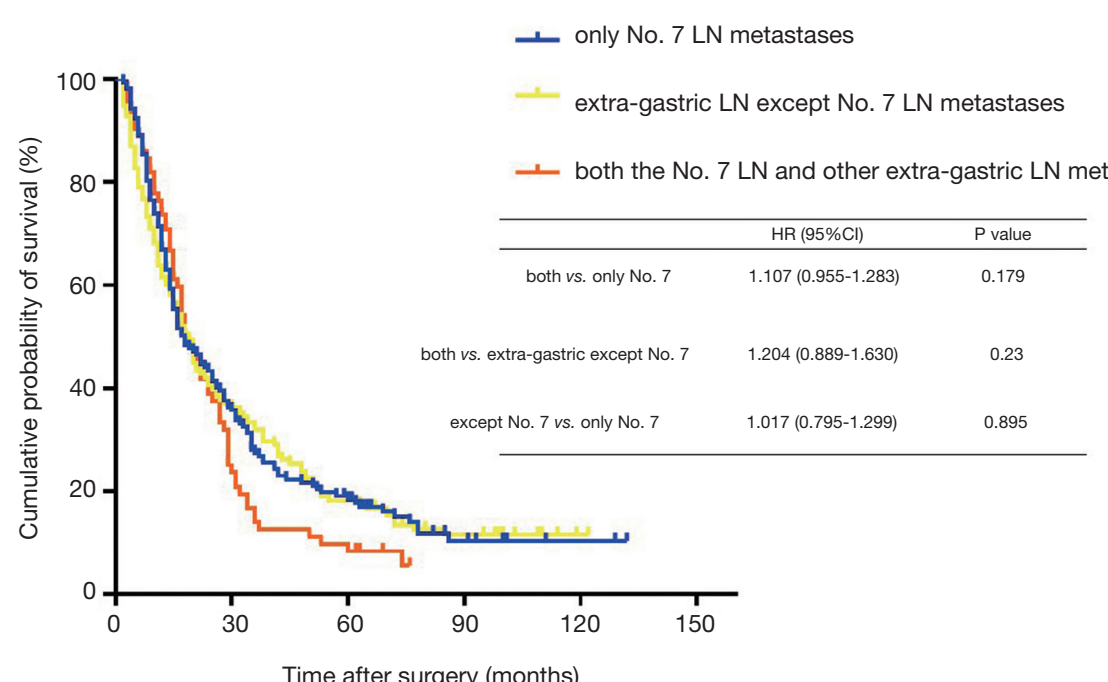

No. at risk

only No. 7

other extra-gastric except No. $7 \quad 138$

both No. 7 and other extra-gastric 72

$\begin{array}{lrrrl}56 & 27 & 7 & 2 & 0 \\ 50 & 25 & 11 & 1 & 0 \\ 17 & 6 & 0 & 0 & 0\end{array}$

Figure 3 Survival analysis for patients with extra-gastric LN metastases. (A) Patients with extra-gastric LN metastases were subdivided into three subgroups: patients with only No. 7 LN metastases, patients with extra-gastric LN except No. 7 LN metastases, and patients with both No. 7 LN and other extra-gastric LN metastases; (B) Kaplan-Meier curves for overall survival among three subgroups. LN, lymph node; No. 7 LN, LN along the left gastric artery; HR, hazard ratio; CI, confidence interval.

\section{Survival analysis for patients with extra-gastric $L N$ metastases except the No. $7 \mathrm{LN}$}

Patients in the extra-gastric group were further subdivided into two subgroups: 138 (37.00\%) patients with extra-gastric LN except No. 7 LN metastases (No. 8a, No. 9, No. 10, No. 11, or No. 12a), and $74(19.84 \%)$ presented with both the No. $7 \mathrm{LN}$ and other extra-gastric LN metastases (Figure 3A). Patients without the No. $7 \mathrm{LN}$ metastases failed to be elucidated to be significantly associated with the higher survival rate compared to other subgroups of patients (Figure 3B), which indicated the No. $7 \mathrm{LN}$ should not be considered as the predictive $\mathrm{LN}$ for the extra-gastric $\mathrm{LN}$ metastases.

\section{Correlation analysis of risk factors for the No. $7 \mathrm{LN}$ metastases}

Among 1,586 patients, 235 (14.82\%) presented with the No. 7 LN metastases. The median number of the No. 7 LNs examined was 2 (range, 1 to 27). As shown in Table 3, 
Table 3 Univariate and multivariate correlation analysis for the No. 7 LN metastases

\begin{tabular}{|c|c|c|c|c|c|c|c|c|}
\hline \multirow{2}{*}{ Variable } & \multicolumn{5}{|c|}{ Univariate analysis } & \multicolumn{3}{|c|}{ Multivariate analysis } \\
\hline & $\mathrm{N}$ & No & Yes & $\chi^{2}$ value & $\mathrm{P}$ & OR & $95 \% \mathrm{Cl}$ & $\mathrm{P}$ \\
\hline \multicolumn{9}{|l|}{ Gender } \\
\hline Male & 1,144 & 974 & 170 & 0.006 & 0.938 & & & \\
\hline \multicolumn{9}{|l|}{ Age } \\
\hline Mean \pm SD & & $60.68 \pm 11.48$ & $61.68 \pm 11.19$ & & 0.217 & & & \\
\hline$<60$ & 698 & 597 & 101 & 0.119 & 0.73 & & & \\
\hline$\geq 60$ & 888 & 754 & 134 & & & & & \\
\hline Middle $1 / 3$ & 134 & 112 & 22 & & & & & \\
\hline Lower $1 / 3$ & 655 & 578 & 77 & & & & & \\
\hline More than $2 / 3$ & 312 & 266 & 46 & & & & & \\
\hline \multicolumn{9}{|l|}{ Tumor size } \\
\hline Mean \pm SD & & $5.50 \pm 3.20$ & $5.77 \pm 2.45$ & & 0.136 & & & \\
\hline$\leq 5.0 \mathrm{~cm}$ & 881 & 766 & 115 & 4.885 & $0.027^{*}$ & & & \\
\hline$>5.0 \mathrm{~cm}$ & 705 & 585 & 120 & & & & & \\
\hline \multicolumn{9}{|c|}{ Number of LNs examined } \\
\hline Pt1a & 21 & 21 & 0 & 17.776 & $0.003^{*}$ & & & \\
\hline Pt1b & 31 & 29 & 2 & & & & & \\
\hline Pt2 & 183 & 167 & 16 & & & & & \\
\hline Pt3 & 107 & 98 & 9 & & & & & \\
\hline Pt4a & 1,195 & 995 & 200 & & & & & \\
\hline Pt4b & 49 & 41 & 8 & & & & & \\
\hline \multicolumn{9}{|l|}{ Pn stage } \\
\hline Pno & 611 & 611 & 0 & 299.754 & $<0.001^{\star \star}$ & 2.358 & $1.84-3.022$ & $<0.001^{\star *}$ \\
\hline Pn1 & 288 & 270 & 18 & & & & & \\
\hline Pn2 & 355 & 265 & 90 & & & & & \\
\hline
\end{tabular}

Table 3 (continued) 
Page 10 of 14

Sun et al. No. 7 lymph node metastasis for gastric cancer

Table 3 (continued)

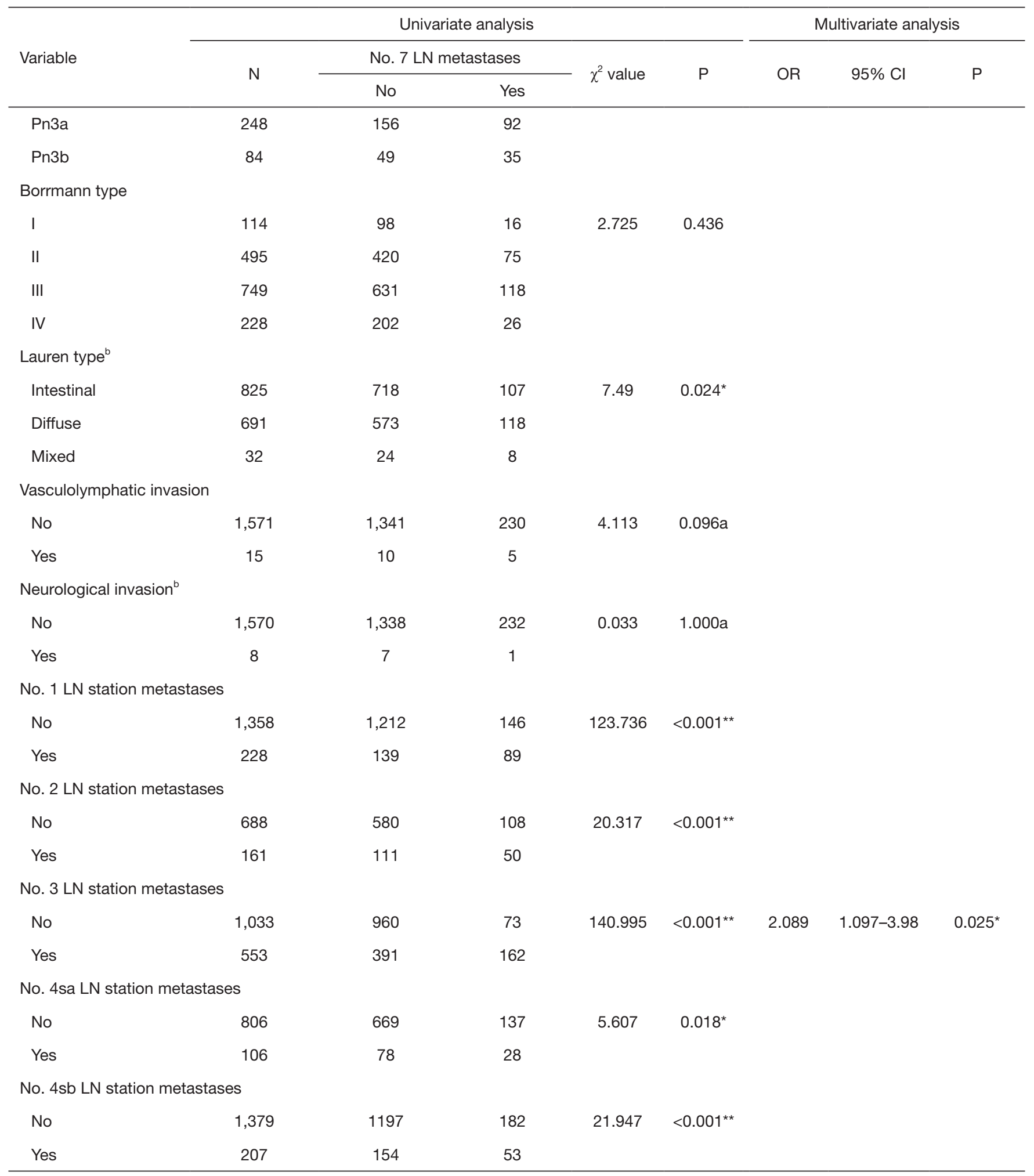

Table 3 (continued) 
Table 3 (continued)

\begin{tabular}{|c|c|c|c|c|c|c|c|c|}
\hline \multirow{2}{*}{ Variable } & \multicolumn{5}{|c|}{ Univariate analysis } & \multicolumn{3}{|c|}{ Multivariate analysis } \\
\hline & $\mathrm{N}$ & No & Yes & $\chi^{2}$ value & $P$ & OR & $95 \% \mathrm{Cl}$ & $\mathrm{P}$ \\
\hline \multicolumn{9}{|c|}{ No. 4d LN station metastases } \\
\hline No & 1558 & 1331 & 227 & 4.272 & $0.072 a$ & & & \\
\hline \multicolumn{9}{|c|}{ No. 5 LN station metastases } \\
\hline No & 1,032 & 915 & 117 & 28.088 & $<0.001^{\star *}$ & 2.023 & $1.021-4.01$ & $0.043^{*}$ \\
\hline Yes & 147 & 107 & 40 & & & & & \\
\hline \multicolumn{9}{|c|}{ No. 6 LN station metastases } \\
\hline
\end{tabular}

${ }^{a}$, continuity correction analysis; ${ }^{b}$, some data missed; ${ }^{*}, \mathrm{P}<0.05 ;{ }^{* \star}, \mathrm{P}<0.001$. LN, lymph node.

the univariate analysis showed that the No. 7 LN metastases were significantly related with thirteen clinicopathologic characteristics: tumor location $(\mathrm{P}=0.014)$, tumor size $(\mathrm{P}=0.027)$, number of $\mathrm{LNs}$ examined $(\mathrm{P}<0.001)$, $\mathrm{pT}$ stage $(\mathrm{P}=0.003)$, pN stage $(\mathrm{P}<0.001)$, Lauren type $(\mathrm{P}=0.024)$, No. $1 \mathrm{LN}$ metastatic status $(\mathrm{P}<0.001)$, No. $2 \mathrm{LN}$ metastatic status $(\mathrm{P}<0.001)$, No. 3 LN metastatic status $(\mathrm{P}<0.001)$, No. 4sa LN metastatic status ( $\mathrm{P}=0.018)$, No. 4sb LN metastatic status $(\mathrm{P}<0.001)$, No. 5 LN metastatic status $(\mathrm{P}<0.001)$ and No. $6 \mathrm{LN}$ metastatic status $(\mathrm{P}<0.001)$. However, $\mathrm{pN}$ stage [odds ratio (OR) 2.358, 95\% confidence interval (CI): 1.840 to 3.022, $\mathrm{P}<0.001$ ], No. $3 \mathrm{LN}$ metastatic status (OR 2.089, 95\% CI: 1.097 to $3.980, \mathrm{P}=0.025)$, and No. $5 \mathrm{LN}$ metastatic status (OR 2.023, 95\% CI: 1.021 to 4.010, $\mathrm{P}=0.043$ ) were identified as independent risk factors for the No. $7 \mathrm{LN}$ metastases by using the multivariate logistic analysis.

\section{Discussion}

In this study, we found that the OS rate of patients with metastases in the No. 7 station in addition to peri-gastric stations was significantly lower than that of patients with metastases in only peri-gastric LN stations. Nevertheless, the survival rate for patients with peri-gastric and No. 7 station metastases was not significantly different from the survival rate for patients with peri-gastric and other extragastric LN metastases. Furthermore, among patients with both peri-gastric and extra-gastric LN metastases, there was no significant difference in survival rate between those with and without No. 7 station metastases. Metastasis in the No. 7 station did not appear to be essential for the development of other extra-gastric LN metastases, indicating that it should not be considered a predictive marker for predicting the invasion extent. Based on survival rate, the No. 7 station seems more closely aligned with the extra-gastric rather than peri-gastric stations.

LN metastases are extremely crucial for evaluating the prognostic outcomes of GC patients, and the precision of LN station staging is critical for deciding the treatment and for evaluating the OS. LN metastases in local peri-gastric area are mainly spreading via complicated lymphatic network and might fellow some orders from N1 station to N2 station $\mathrm{LN}$, which gives us potential opportunities to find some mark LN stations to predict the extent of LN metastases and lymphadenectomy. Nevertheless, the skip LNs were reported as the presence of a metastatic LN in an extragastric area without peri-gastric LN involvement, which fortunately were relatively rare. In our entire 1923 GC patients, we observed the lower occurrence rate $(65 / 1923$, $3.38 \%)$ of skip metastases and highest frequency (32/65, $49.23 \%$ ) of skip metastases of No. 7 LN station (Figure S2), which was consistent with most studies $(27,28)$. As many previous studies reported $(29,30)$, we found survival rate of patients with skip metastases was close to that of patients with only peri-gastric LN metastases (HR 0.965, 95\% CI: $0.910-1.022, \mathrm{P}=0.225$ ), whereas was significantly superior 
than that of NO. 7 group (HR 0.910, 95\% CI: 0.839-0.986, $\mathrm{P}=0.021$ ). Considering the specific clinical characteristic of skip metastases and the high frequency of skip metastases of No. 7 LN station, our study excluded this subgroup patients to obtain precise conclusion.

Currently, dissection of the No. $7 \mathrm{LN}$ is deemed a part of the D1 LN dissection range (4), instead of the D2 dissection range (as per the previous definition) (20). In this study, the metastatic incident rate of the No. $7 \mathrm{LN}$ station was $14.82 \%(235 / 1,586)$ in the entire cohort, which was the $3^{\text {rd }}$ highest metastatic incident rate among all LN stations, only ranking lower than the rates of the No. $3(544 / 1,586)$ and No. $6(301 / 1,170)$ LN stations. Therefore, the No. $7 \mathrm{LN}$ station might be considered as the main route of lymphatic drainage from the gastric area. Our previous study also reported a high metastatic incident rate in the No. 7 LN station in GC patients (2). Other researchers have similarly reported that the metastatic incident rate of the No. 7 LN station was comparable to or even higher than that of the peri-gastric LN stations $(1,31)$. This high metastatic incident rate might be the reason that the No. $7 \mathrm{LN}$ station was reclassified in the range of D1 LN dissection in the $3^{\text {rd }}$ edition of the Japanese Gastric Cancer Treatment Guidelines and in the $14^{\text {th }}$ edition of the Japanese General Rules for Gastric Cancer Study $(4,5)$. However, it is still controversial whether the prognostic implication of the No. $7 \mathrm{LN}$ station is similar to that of the peri-gastric LN stations or other extra-gastric LN stations and whether the No. 7 station might be considered as an SLN for extragastric LN metastases in GC patients.

In the entire cohort, No. $7 \mathrm{LN}$ metastases showed a significant impact on $\mathrm{OS}$ rate $(\mathrm{P}<0.001)$. After stratification by pTNM stage, we observed similar results in patients with pIII stage $(\mathrm{P}=0.014)$. We also observed a similar nonsignificant trend in $\mathrm{pII}$ stage patients (shown in the Figure $1 B$ ), which might be a result of the small sample size of these GC patient subgroups. Our results were consistent with those reported by Chen (32). Nevertheless, another study reported contrasting results after adjustment for $\mathrm{pN}$ stage, because two-thirds of their patient population received preoperative therapy to downstage the $\mathrm{pN}$ stage (33). Furthermore, the small sample size might limit the credibility of the results of that study. In despite of those limitations, we also observed some tendency of poor outcome in patients with No.7 LN metastases (with No. $7 \mathrm{LN}$ metastases $v s$. without No. $7 \mathrm{LN}$ metastases, 3-year survival rate: $\mathrm{N} 1,75 \%$ vs. $79 \%$; $\mathrm{N} 2,40 \%$ vs. $80 \%$; N3, $20 \%$ vs. $33 \%$ ). Thus, we could not deny that No. $7 \mathrm{LN}$ station metastases might have a significant influence on the prognosis of GC patients.

To obtain more precise results, PSM was performed to balance the confounding factors between two groups. Both before and after PSM, the survival outcome of patients with No. 7 LN station metastases was similar to that of patients with extra-gastric LN station metastases (Figure 2C,E) and significantly poorer than that of patients with only perigastric LN station metastases (Figure 2B,D). Our results were consistent with those reported by Chen et al. (32). However, Murayama et al. reported that the prognostic impact of the No. 7 LN station was similar to that of perigastric LNs in patients with six or fewer positive LNs (6). This converse conclusion might be achieved result from enriching patients with lack of positive LNs. Based on our findings, we believe that the No. $7 \mathrm{LN}$ station should be included in the range of D2 lymphadenectomy. If No. $7 \mathrm{LN}$ involvement is highly suspected during the operation, D2 lymphadenectomy might be required. However, our study showed that metastases to extra-gastric LNs other than the No. 7 LN was observed in 37\% (138/373) of patients, and this subgroup did not show a superior survival outcome. This result indicated that No. $7 \mathrm{LN}$ metastasis was not essential for extra-gastric LN metastases and that the No. 7 LN should not be considered as the SLN for extra-gastric LN metastases. Further prospective large-scale studies are warranted to confirm this conclusion.

The results of multivariate analysis showed $\mathrm{pN}$ stage $(\mathrm{P}<0.001)$, No. 3 LN metastases $(\mathrm{P}=0.025)$, and No. $5 \mathrm{LN}$ metastases $(\mathrm{P}=0.043)$ were independent risk factors for No. $7 \mathrm{LN}$ metastases. Chen et al. also reported that metastases to the No. $7 \mathrm{LN}$ station were associated with $\mathrm{pN}$ stage, pTNM stage, and No. 3 LN metastases, which is mostly consistent with our findings (32). In addition, previous studies have reported that No. $7 \mathrm{LN}$ metastases are associated with aggressive biological behavior, such as large tumor size and vasculolymphatic invasion $(34,35)$. These findings indicated that the No. 7 station might be a part of a crucial lymphatic route.

This study has several limitations. First, the endpoint in this study was OS; we did not investigate disease-free survival. Second, our study had a single-center retrospective design. Third, our study had a relatively small sample size. Third, the patients lost to follow up were excluded in this study, lesser than $10 \%$ of entire cohort, which might cause small amount of selection bias. Thus, there is a need for a multicenter study with a larger sample size to confirm our findings. 


\section{Conclusions}

In conclusion, our study indicated the No. $7 \mathrm{LN}$ station should be reclassified in the $\mathrm{D} 2$ dissection range due to its prognostic impact similar to that of extra-gastric LN station. If No. $7 \mathrm{LN}$ involvement is highly suspected during the operation, D2 lymphadenectomy might be required. Nonetheless, our study proposed that the No. $7 \mathrm{LN}$ station should not be considered a SLN as it does not appear to be essential for extra-gastric LN metastasis.

\section{Acknowledgments}

We would like to thank Editage (www.editage.com) for English language editing.

Funding: This study was supported by grants from the Programs of National Natural Science Foundation of China [grant number 81572372 to JD], National Key Research and Development Program "major chronic non-infectious disease research" [grant number 2016YFC1303202 to HL], National Key Research and Development Program "precision medicine research" [grant number 2017YFC0908304 to JD].

\section{Footnote}

Reporting Checklist: The authors have completed the STROBE reporting checklist. Available at http://dx.doi. org/10.21037/atm-19-4786a

Data Sharing Statement: Available at http://dx.doi. org/10.21037/atm-19-4786a

Peer Review File: Available at http://dx.doi.org/10.21037/atm19-4786a

Conflicts of Interest: All authors have completed the ICMJE uniform disclosure form (available at http://dx.doi. org/10.21037/atm-19-4786a). The authors have no conflicts of interest to declare.

Ethical Statement: The authors are accountable for all aspects of the work in ensuring that questions related to the accuracy or integrity of any part of the work are appropriately investigated and resolved. The study was approved by Tianjin Medical University Cancer Institute and Hospital ethics committees (No. bc2019087). All patients provided written informed consent before any enrolling procedures were initiated.
Open Access Statement: This is an Open Access article distributed in accordance with the Creative Commons Attribution-NonCommercial-NoDerivs 4.0 International License (CC BY-NC-ND 4.0), which permits the noncommercial replication and distribution of the article with the strict proviso that no changes or edits are made and the original work is properly cited (including links to both the formal publication through the relevant DOI and the license). See: https://creativecommons.org/licenses/by-nc$\mathrm{nd} / 4.0 /$.

\section{References}

1. Sun Z, Wang ZN, Zhu GL, et al. Advanced gastric cancer with early cancer macroscopic appearance: is it worthy of D2 lymphadenectomy? Ann Surg Oncol 2010;17:1278-90.

2. Liang J, Liang H, Deng J, et al. Clinical study on lymph node metastasis regularity in 1456 patients with gastric cancer. Zhonghua Wei Chang Wai Ke Za Zhi 2018;21:1154-60.

3. Ajani JA, Bentrem DJ, Besh S, et al. Gastric cancer, version 2.2013: featured updates to the NCCN Guidelines. J Natl Compr Canc Netw 2013;11:531-46.

4. Japanese Gastric Cancer Association. Japanese classification of gastric carcinoma: 3rd English edition. Gastric Cancer 2011;14:101-12.

5. Japanese Gastric Cancer Association. Japanese Classification of Gastric cancer. 14th edition. Tokyo, Japan: Kanehara \& Co. Ltd, 2010.

6. Murayama Y, Ichikawa D, Kubota T, et al. Prognostic impact of lymph node metastasis along the left gastric artery in gastric cancer. Hepatogastroenterology 2011;58:1603-6.

7. Ohdaira $\mathrm{H}, \mathrm{Nimura} \mathrm{H}$, Takahashi $\mathrm{N}$, et al. The possibility of performing a limited resection and a lymphadenectomy for proximal gastric carcinoma based on sentinel node navigation. Surg Today 2009;39:1026-31.

8. Mikami K, Hirano Y, Futami K, et al. Expansion of lymph node metastasis in mixed-type submucosal invasive gastric cancer. Asian J Surg 2018;41:462-6.

9. Sun ZQ, Zhou YB. Study on No. 7 lymph nodes micrometastasis in patients with node- negative gastric carcinoma by routine examination. Zhonghua Wei Chang Wai Ke Za Zhi 2005;8:339-42.

10. Morton DL, Wen DR, Wong JH, et al. Technical details of intraoperative lymphatic mapping for early stage melanoma. Arch Surg 1992;127:392-9.

11. Shi H, Yan R, Wu L, et al. Tumor-targeting CuS 
nanoparticles for multimodal imaging and guided photothermal therapy of lymph node metastasis. Acta Biomater 2018;72:256-65.

12. Kim MC, Kim HH, Jung GJ, et al. Lymphatic mapping and sentinel node biopsy using $99 \mathrm{~m}$ Tc tin colloid in gastric cancer. Ann Surg 2004;239:383-7.

13. Farzaneh F, Moridi A, Azizmohammadi Z, et al. Value of Sentinel Lymph Node (SLN) Mapping and Biopsy using Combined Intracervical Radiotracers and Blue Dye Injections for Endometrial Cancer. Asian Pac J Cancer Prev 2017;18:431-5.

14. Kitagawa Y, Fujii H, Mukai M, et al. The role of the sentinel lymph node in gastrointestinal cancer. Surg Clin North Am 2000;80:1799-809.

15. Kitagawa Y, Kitajima M. Gastrointestinal cancer and sentinel node navigation surgery. J Surg Oncol 2002;79:188-93.

16. Ichikura T, Sugasawa H, Sakamoto N, et al. Limited gastrectomy with dissection of sentinel node stations for early gastric cancer with negative sentinel node biopsy. Ann Surg 2009;249:942-7.

17. Ohdaira H, Nimura H, Mitsumori N, et al. Validity of modified gastrectomy combined with sentinel node navigation surgery for early gastric cancer. Gastric Cancer 2007;10:117-22.

18. Kitagawa Y, Takeuchi H, Takagi Y, et al. Sentinel node mapping for gastric cancer: a prospective multicenter trial in Japan. J Clin Oncol 2013;31:3704-10.

19. Sobin L GM, Witterkind C, et al. TNM classification of malignant tumors. 7th edition. International Union Against Cancer (UICC). New York: Wiley, 2009.

20. Japanese Gastric Cancer Association. Japanese Classification of Gastric Carcinoma - 2nd English Edition. Gastric Cancer 1998;1:10-24.

21. Choi YY, An JY, Guner A, et al. Skip lymph node metastasis in gastric cancer: is it skipping or skipped? Gastric Cancer 2016;19:206-15.

22. Zhao P, Su X, Ge T, et al. Propensity score and proximity matching using random forest. Contemp Clin Trials 2016;47:85-92.

23. Austin PC. The use of propensity score methods with survival or time-to-event outcomes: reporting measures of effect similar to those used in randomized experiments. Stat Med 2014;33:1242-58.

24. Han HS, Shehta A, Ahn S, et al. Laparoscopic versus open liver resection for hepatocellular carcinoma: Case- matched study with propensity score matching. J Hepatol 2015;63:643-50.

25. Brookhart MA, Schneeweiss S, Rothman KJ, et al. Variable selection for propensity score models. Am J Epidemiol 2006;163:1149-56.

26. D'Agostino RB Jr. Propensity score methods for bias reduction in the comparison of a treatment to a nonrandomized control group. Stat Med 1998;17:2265-81.

27. Su Z, Shu K, Zheng M, et al. Sentinel lymph node and skip metastases in gastric cancer: a prospective study. Hepatogastroenterology 2013;60:1513-8.

28. Zhao B, Mei D, Zhang J, et al. Impact of skip lymph node metastasis on the prognosis of gastric cancer patients who underwent curative gastrectomy. J BUON 2019;24:693-700.

29. Saito H, Tsujitani S, Ikeguchi M. Clinical significance of skip metastasis in patients with gastric cancer. Gastric Cancer 2007;10:87-91.

30. Kim DH, Choi MG, Noh JH, et al. Clinical significance of skip lymph node metastasis in gastric cancer patients. Eur J Surg Oncol 2015;41:339-45.

31. Zhu HT, Zhao YL, Wu YF, et al. Features of metastasis in different lymph node groups and their significance in lymph node dissection in total gastrectomy for gastric cancer. Zhonghua Zhong Liu Za Zhi 2008;30:863-5.

32. Chen JH, Cai SR, Zhai ET, et al. Survival prognosis and clinicopathological features of the lymph nodes along the left gastric artery in gastric cancer: implications for D2 lymphadenectomy. Int J Clin Exp Pathol 2015;8:14365-73.

33. Ikoma N, Blum M, Estrella JS, et al. Left Gastric Artery Lymph Nodes Should Be Included in D1 Lymph Node Dissection in Gastric Cancer. J Gastrointest Surg 2017;21:1563-70.

34. Park JM, Jang YJ, Kim JH, et al. Gastric cancer histology: clinicopathologic characteristics and prognostic value. J Surg Oncol 2008;98:520-5.

35. Liu E, Zhong M, Xu F, et al. Impact of lymphatic vessel invasion on survival in curative resected gastric cancer. J Gastrointest Surg 2011;15:1526-31.

Cite this article as: Sun W, Deng J, He W, Liu J, Guo S, Gu P, Wu Z, Liang H. Should the left gastric artery lymph node be considered as the predictive lymph node for extra-gastric lymph node metastases? Ann Transl Med 2020;8(11):680. doi: 10.21037/atm-19-4786a 


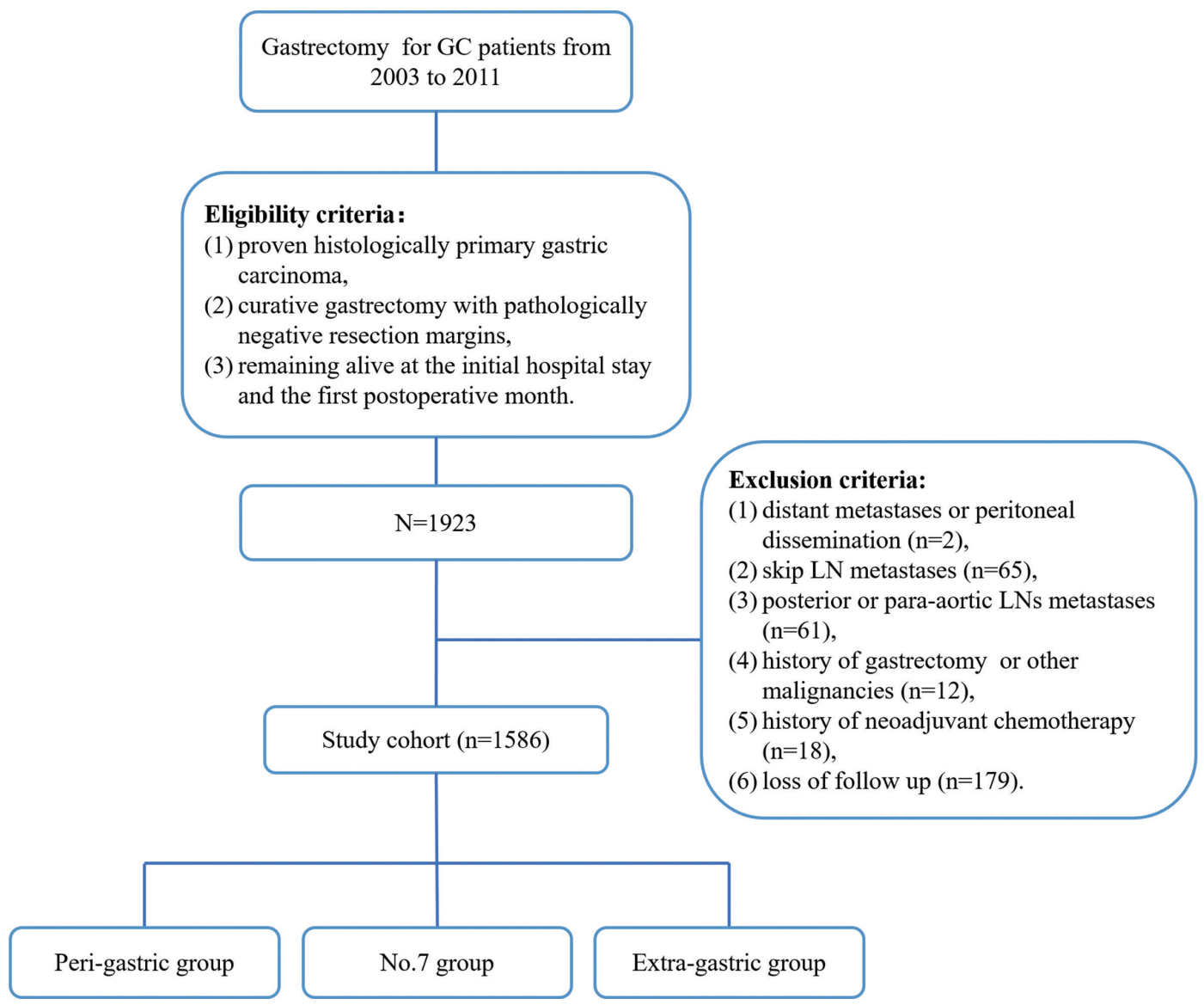

Figure S1 Patients flow diagram: eligibility criteria and exclusion criteria in this study. GC, gastric cancer; LN, lymph node. 


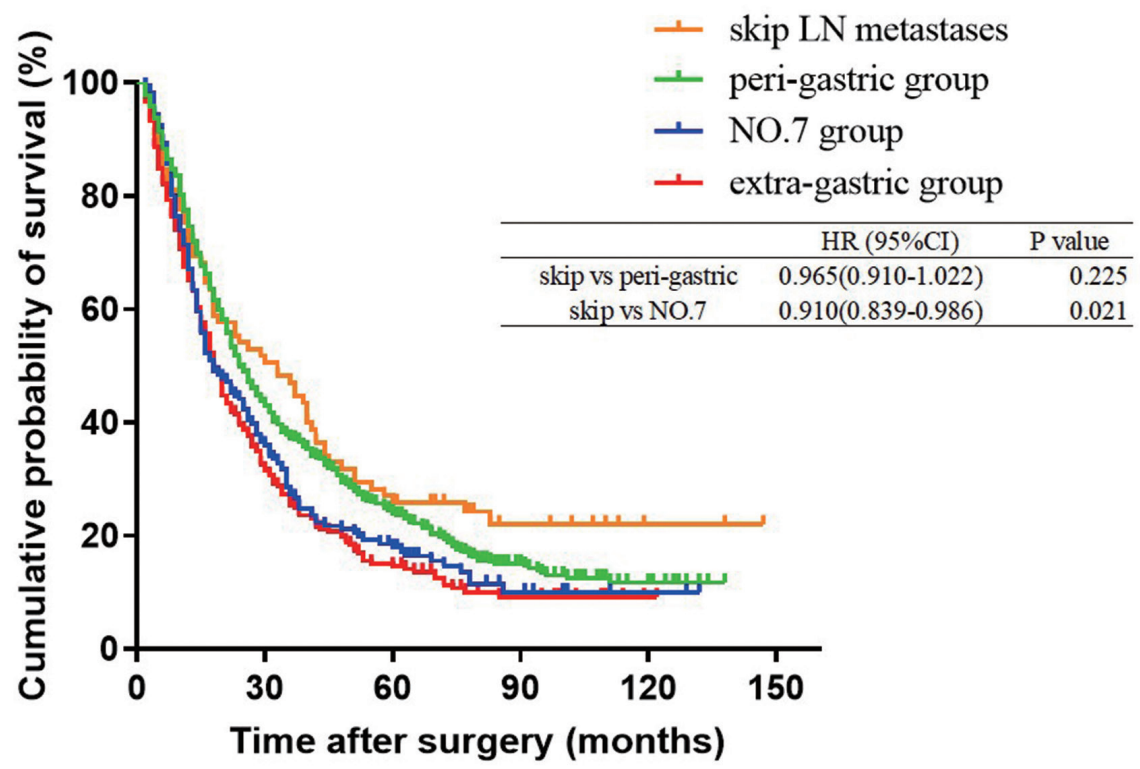

No. at risk

$\begin{array}{crrrrrr}\text { skip LN } & 65 & 36 & 16 & 6 & 1 & 0 \\ \text { peri-gastric } & 524 & 225 & 121 & 39 & 11 & 0 \\ \text { NO.7 } & 161 & 58 & 27 & 7 & 2 & 0 \\ \text { extra-gastirc } & 212 & 67 & 31 & 11 & 1 & 0\end{array}$

Figure S2 Survival analysis for patients with skip LN metastases. LN, lymph node; No. 7 LN, LN along the left gastric artery; HR, hazard ratio; CI, confidence interval. 